\title{
Evaluation of degradation mechanism of chlorhexidine by means of Density Functional Theory calculations
}

\author{
Michele Aparecida Salvador ${ }^{\mathrm{a}, *}$, Camila Pinheiro Sousa ${ }^{\mathrm{b}}$, Simone Morais ${ }^{\mathrm{c}}$, \\ Pedro de Lima-Neto ${ }^{b}$, Adriana Nunes Correia ${ }^{b}$, Paula Homem-de-Mello ${ }^{a, *}$ \\ a Centro de Ciências Naturais e Humanas, Universidade Federal do ABC, Av. dos Estados, 5001, Bloco B, sala 1017, 09210-580, Santo André - SP, Brazil \\ b Departamento de Química Analítica e Físico-Química, Centro de Ciências, Universidade Federal do Ceará, Bloco 940, Campus do Pici, 60440-900, Fortaleza - \\ CE, Brazil \\ C REQUIMTE-LAQV, Instituto Superior de Engenharia do Porto, Instituto Politécnico do Porto, R. Dr. António Bernardino de Almeida 431, 4200- \\ 072, Porto, Portugal
}

Keywords:
Density
Functional
Theory
Chlorhexidine
Oxidation mechanism

\begin{abstract}
Chlorhexidine (CHD), a germicidal drug, has degradation products that can be hemotoxic and carcinogenic. However, there is no consensus in literature about the degradation pathway. In order to shed light on that mechanism, we have employed Density Functional Theory to study reactants, in different protonation states, products and intermediates involved in the different pathways. Based on free energy values comparison and frontier molecular orbital analysis, we have obtained the most stable structures in each protonation state. CHD in saturated form has HOMO localized in one $p$ chloroaniline, and, due to molecule's symmetry, HOMO-1 has contributions from the other side of the molecule, but mainly from the biguanide portion of the molecule, instead of from the $p$-chloroaniline. For the saturated form, we have studied two possible degradation pathways, starting from the monoprotonated structure, and three pathways starting from the neutral structure. We found out that the mechanisms proposed in literature, whose pathways lead to $p$-chloroaniline (PCA) formation in a smaller number of steps, are more likely than the mechanisms with more intermediate steps or pathways that do not predict PCA formation. Also, based on free energy results, we have found that the formation of another sub-product (PBG-AU) is favorable as well.
\end{abstract}

\section{Introduction}

2.

Computational chemistry has been reported as an efficient tool to clarify kinetic and thermodynamic processes involved in synthesis, properties characterization (Matencio et al., 2017; Berzins et al., 2016) and degradation pathways of molecules and structures, especially pharmaceutical drugs (Silva et al., 2017; Rapolu et al., 2015). Its combination with experimental techniques appears as an interesting study field, since degradation products could become their use unfeasible. Indeed, electrochemical behavior and oxidation reactions could be better understood in association with theoretical evaluations (Silva et al., 2017).

However, we have not found any computational study about the oxidation mechanism of chlorhexidine (CHD), a widely used drug. Chlorhexidine (CHD) is a pharmaceutical drug composed by two (p-chlorophenyl) biguanide (PBG) portions bonded by a hexane chain. It is positively charged and reacts with the negatively charged microbial cell surface, destroying the integrity of the cell membrane (NCBI, 2015), therefore being widely used because of its germicidal activity against bacteria, yeasts, and molds (Wang and Tsai, 2001; Jones et al., 1998; Leitune et al., 2010; Fong et al., 2010; Pusateri et al., 2009; Edmiston et al., 2007; Lindblad et al., 2010; Loguercio et al., 2009; Ji et al., 2010). Although the use in mouthwash formulations, toothpaste and disinfectant solutions have been effective, CHD's stability is limited by the appearance of $p$-chloroaniline (PCA), which is its primary degradation product, known as being hemotoxic and quickly absorbed and metabolized, as well as being carcinogenic (Wang and Tsai, 2001; Zong and Kirsch, 2012). 

(a)<smiles>N=C(NCCCCCCNC(=N)Nc1ccc(Cl)cc1)NC(=N)Nc1ccc(Cl)cc1</smiles>

(b)<smiles>NC(=NCCCCCCN=C(N)Nc1ccc(Cl)cc1)N=C(N)Nc1ccc(Cl)cc1</smiles>

Fig. 1. Two possible neutral structures for CHD: in (a) CHD's saturated chain and in (b) CHD's unsaturated chain. Numbers indicate protonable $\mathrm{N}$ atoms.

There are different proposed structural forms of neutral CHD, as shown in Fig. 1, being (a) the neutral form with a saturated chain and two pairs of nitrogen atoms bonded to the chain by unsaturated bonds (NCBI, 2015; Anon.,2017) as presented by Wang and Tsai (2001), and (b) the neutral form with an unsaturated chain, as proposed byVan Oosten et al. (2014), and Blackburn et al. (2007). Bharatam et al. (2005) represented CHD with unsaturated bonds as its neutral structure (Fig1(b)), and attributed its chemical, biochemical, and therapeutic activities to the electron distribution in the system.

The commercial form (Fig. 1(a)) of the drug is doubly positively charged and available in acetate, gluconate and hydrochloride forms (Ha and Cheung, 1996). As can be seen for both neutral proposed structures of CHD, this is a symmetric molecule, and different forms of protonation have been reported in acidic conditions, with two (Anon., 2017) or four (NCBI, 2015) protonated nitrogen atoms. Wang and Tsai (2001) suggested that each PBG portion has two nitrogen atoms with unsaturated bonds, leading to two protonable sites.

Different pathways to CHD's degradation in acidic medium have been proposed (Edmiston et al., 2007; Anon., 2017; Van Oosten et al.,2014); even though $\mathrm{Ha}$ and Cheung (1996) reported degradation pathways under alkaline conditions, we focused on acidic media since most of the experimental work was done under this condition. In acidic conditions, CHD's degradation lead to PCA formation (Edmiston et al., 2007; Anon., 2017; Van Oosten et al., 2014), but $p$-chlorophenyl-biguanidine (PCPG) and phenylbiguanidine have been reported as degradation products as well, being the latter a photolysis product (Zong and Kirsch, 2012). Revelle et al. (1993) reported the identification of 11 degradation products by High-Performance Liquid Chromatography and Mass Spectrometry (HPLC-MS), six of them representing new compounds, and various degradation mechanisms were proposed for different stress conditions. They suggested that the main decomposition product under thermal stress is the so-called impurity G (referred as PBG-G by Wang et al.).

Taking these apparently conflicting experimental results into account, in this work we aim to shed light on the oxidation process of chlorhexidine, starting from different neutral forms, and by considering various protonation sites. In a previous work (Sousa et al., 2017) we performed quantum mechanical calculations simulations and free energy studies to support electrochemical studies on CHD oxidation, focusing on the adsorption process. Here, we extend that study in order to give a molecular insight about the effects of the protonation states on degradation pathway of CHD. The evaluation of the stability of intermediates and products of this degradation process can aid for example, in developing new formulations and drug delivery systems (Fernandes et al., 2014).

\section{Methodology}

We have studied different states of protonation for CHD and also possible intermediates and products of degradation proposed in literature, mainly in references (Zong and Kirsch, 2012; Ha and Cheung, 1996), namely:( $p$-chlorophenyl)urea (PCPU), ( $p$ - chlorophenyl)guanidine (PCPG), [( $p$-chlorophenyl)amidino]urea (PBG$\mathrm{AU})$, and N-amidino-N'-( $p$-chlorophenyl)urea (PBG-APU). We have employed Density Functional Theory (DFT), because it is the methodology that best predicts electronic and structural properties of molecular systems, allowing even the study of reaction mechanisms at a feasible computational cost (Gino DiLabio and Otero-de-la-Roza, 2014; Fernandes and Joa, 2007; Capelle, 2006; Geerlings, 2003).

In this way, we have optimized the geometries of proposed structures by means of B3LYP hybrid functional and 6-311G(d) basis set. Frequency calculations were carried out to ensure structures obtained are minima in the potential energy surface. From these calculations, we have obtained also free energies of formation of each compound (reactant in different protonation states, as well as possible intermediates and products) to evaluate the oxidation mechanisms. Time-Dependent Density Functional Theory (TD-DFT) calculations with B3LYP/6-311G(d) were carried out to obtain the frontier molecular orbital energies. All calculations were performed with Gaussian 09 package (Frisch et al., 2010). The values of Root Mean Square Deviation (RMSD), that quantifies the differences among geometries, was calculated using VMD software (Humphrey et al., 1996). MarvinSketch tool (ChemAxon, 2015), was used to estimate the pKa of the different

Table 1

Molecular orbitals energies (obtained via TD-DFT Calculations) and free energy of formation (DG) (a.u.) for CHD neutral and charged species.

\begin{tabular}{lll}
\hline & saturated CHD & unsaturated CHD \\
\hline LUMO & -0.04288 & -0.03583 \\
HOMO & -0.20759 & -0.21442 \\
HOMO-1 & -0.21709 & -0.21778 \\
HOMO-2 & -0.23463 & -0.21942 \\
DG (neutral) & -2324.249669 & -2324.246721 \\
DG (charge +1) & -2324.002500 & -2324.007668 \\
DG (charge +2$)$ & -2323.675495 & -2323.704822 \\
\hline
\end{tabular}


protonation sites for $\mathrm{CHD}$, even though empirical data were also considered for comparison.

\section{Results and discussion}

First of all, we have considered the two neutral forms of CHD as described in literature and presented in Fig. 1. Table 1 presents the energy values of the frontier orbitals LUMO (lowest unoccupied molecular orbital), HOMO (highest occupied molecular orbital), HOMO-1, HOMO-2, and also Gibbs free energy (DG) for these two structures. The difference between DG is approximately 0.003 a.u. ( $\mathrm{r} 1.85 \mathrm{kcal} \mathrm{mol}^{-1}$ ), being the saturated form the most stable. The values of RMSD calculated between these two structure backbones was $2.6 \AA$, originated mainly by the difference in biguanide units which confers an angle of almost $90^{\circ}$ between phenylic ring and hexane chain for the unsaturated form. So, the most stable form (saturated) is also the more linear structure. The superposition between the structures can be found in Supplementary material (SM1).

From Table 1, it is also possible to verify that the unsaturated structure has occupied molecular orbitals almost degenerated: HOMO, HOMO-1 and HOMO-2 energy values are quite similar:for the saturated CHD, the difference |HOMO-HOMO-1| is about 6 kcal $\mathrm{mol}^{-1}$ and the difference $\mid$ (HOMO-1)-(HOMO-2)| is about 1 $\mathrm{kcal} \mathrm{mol}^{-1}$; for the unsaturated CHD, the differences are around 1$2 \mathrm{kcal} \mathrm{mol}^{-1}$ in both cases. Along this work, we paid attention to HOMO and HOMO-1 orbitals because of oxidation processes involved in degradation of CHD.

CHD in saturated form has HOMO localized in one $p$-chloroaniline ('right side'), and, since molecule is symmetric, we expected the next orbitals to be located in the other $p$-chloroaniline. However, even though HOMO-1 has contributions from the other side of the molecule (see Fig. 2(a) and (b)), it is composed mainly from the biguanide portion of the molecule. On the other hand, unsaturated form has HOMO and HOMO-1 almost degenerated and less localized, with contributions from both sides of the compound, even if HOMO has more important contributions from atoms in the right side of the molecule, and the HOMO- 1 from the left side of the molecule contributions (see Fig. 2(c) and (d)).

The abstraction of one and two electrons of these neutral molecules was also investigated in order to evaluate possible oxidation products. Free energies of formation are also presented on Table 1. Oxidation products of unsaturated CHD are more stable than products of saturated CHD, probably because HOMO and HOMO-1 of unsaturated form are spread over a larger portion of the molecule. CHD is mainly used in its protonated form. Previous experimental and theoretical studies indicated two main pKa, about 10 and 2 (Blackburn et al., 2007; ChemAxon, 2015; Hugo and Longworth, 1964; Qi et al., 1994; Agarwal et al., 2012). Blackburn (Blackburn et al., 2007) presented an estimate of pKa by means of empirical simulations, suggesting that at $\mathrm{pHrv} 10.1 \mathrm{CHD}$ is monoprotonated and at $\mathrm{pH} \mathrm{rv} 9.5$ it is diprotonated. At lower $\mathrm{pH}$ $(<2.5)$, CHD may be four-folded protonated. Before studying the degradation pathways, we have proceeded with a careful examination of the relative stability of all possible protonation forms. For the unsaturated form, we have considered one and two $\mathrm{N}$ atoms protonated. In case of only one protonation, there are two possibilities: on $\mathrm{N} 22$ and N42, both atoms localized nearer the hexane chain than the phenylic ring. HOMO is localized on the opposite site of protonated $\mathrm{N}$ atom, for both cases. Table 2shows energy values for HOMO and HOMO-1 for both mono-protonation possibilities, and the free energy of formation (DG). DG indicates the structure protonated on $\mathrm{N} 42$ is more stable than the protonated on N22 about 0.001 a.u, i.e. $2.6 \mathrm{~kJ} \mathrm{~mol}^{-1}$, which justifies the two pKa's rv 10 presented in previous works (Van Oosten et al., 2014; Blackburn et al., 2007). HOMO and HOMO-1 are almost degenerated for the N42-protonated structure. As free energy of formation is almost equal for both structures, the protonation of both sites may occur simultaneously, so we have studied the (N22, $\mathrm{N} 42$ ) protonated form. In this case, HOMO is localized over the left chlorine ring, but right ring also contributes for this molecular orbital, while HOMO-1 is located on the right side of the molecule. For this reason, HOMO and HOMO-1 are degenerated, what reflects the symmetry of the doubly protonated specie.

Saturated form is the most stable neutral form of CHD. In this case, we have analyzed the protonation of one and two nitrogen atoms, as indicated in Fig. 1(a). First of all, we have examined the monoprotonation: DG, HOMO and HOMO-1 energies are presented in Table 2. As mentioned before, literature usually points out only two pKa's values (Hugo and Longworth, 1964; Qi et al., 1994; Agarwal et al., 2012; Xue et al., 2009). This is expected because CHD is symmetric in relation to the hexane chain: N2O and $\mathrm{N} 45$ should be protonated at the same (or very similar) $\mathrm{pH}$, while $\mathrm{N} 15$ and $\mathrm{N} 52$ in other $\mathrm{pH}$. In fact, the protonation of $20 \mathrm{~N}$ and $45 \mathrm{~N}$ yields more stable structures, about 0.02 a.u. $\left(14 \mathrm{kcal} \mathrm{mol}^{-1}\right)$, than the protonation of the nitrogen atoms nearer to the $p$ - (a)

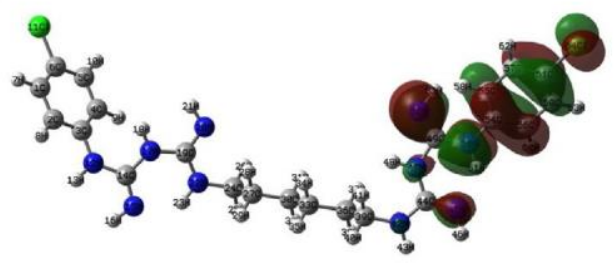

(c)

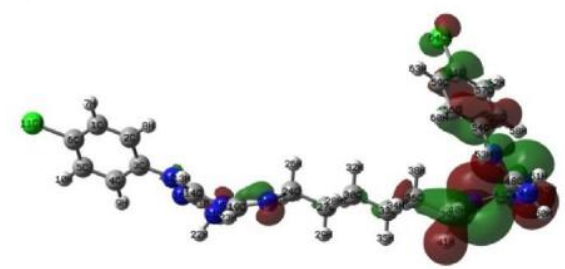

(b)

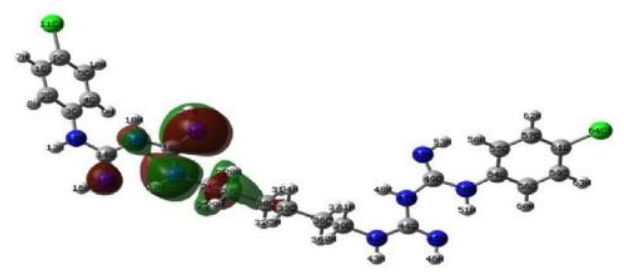

(d)

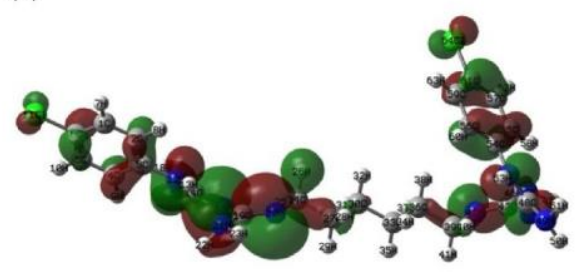

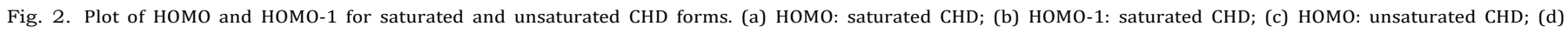
HOMO-1: unsaturated CHD. 
Table 2

Energy of HOMO and HOMO-1 (D is the difference between HOMO and HOMO-1), and DG (all values in a.u.) for different protonated sites of unsaturated (Unsat.) and saturated (Sat.) CHD.

\begin{tabular}{|c|c|c|c|c|c|}
\hline & protonation site & $\mathrm{DG}$ & номо & НОМО-1 & $\mathrm{D}_{\text {|номо-номо-1| }}$ \\
\hline Unsat. CHD & N22 (10.54)* & -2324.659875 & -0.26641 & -0.28342 & 0.01701 \\
\hline Unsat. CHD & N42 (9.94)* & -2324.660872 & -0.26629 & -0.26777 & 0.00148 \\
\hline Unsat. CHD & $\mathrm{N} 22$ and N42 & -2325.024481 & -0.39499 & -0.39500 & 0.00001 \\
\hline Sat. CHD & N15 (7.63)* & -2324.6081 & -0.26246 & -0.29166 & 0.02920 \\
\hline Sat. CHD & N20 (10.45)* & -2324.6307 & -0.26429 & -0.28934 & 0.02505 \\
\hline Sat. CHD & N45 (9.85)* & -2324.6247 & -0.27017 & -0.28078 & 0.01061 \\
\hline Sat. CHD & N52 (8.22)* & -2324.6080 & -0.28003 & -0.29610 & 0.01617 \\
\hline Sat. CHD & $\mathrm{N} 15-\mathrm{N} 45$ & -2324.9521 & -0.39087 & -0.42199 & 0.03112 \\
\hline Sat. CHD & N15 - N52 & -2324.9546 & -0.40519 & -0.41844 & 0.01325 \\
\hline Sat. CHD & $\mathrm{N} 20-\mathrm{N} 45$ & -2324.9437 & -0.38997 & -0.39320 & 0.00323 \\
\hline Sat. CHD & $\mathrm{N} 20-\mathrm{N} 52$ & -2324.9458 & -0.38490 & -0.40877 & 0.02387 \\
\hline Sat. CHD & four-folded protonated & -2325.3162 & -0.54474 & -0.55295 & 0.00821 \\
\hline
\end{tabular}

chloroaniline, $15 \mathrm{~N}$ and $52 \mathrm{~N}$. Regarding HOMO, this is located in the opposite side in relation to the protonation site. N45 protonated form is the only one which HOMO does not include the ring. HOMO and HOMO-1 energies are more similar, almost degenerated, for
N45 and N52 protonated species, as can be seen from $\mathrm{D}_{\text {|номо- }}$ номо-1| in Table 2.

The second approach to evaluate the protonation process was to do simultaneous protonations. For the double protonation on $\mathrm{N}$

(a)

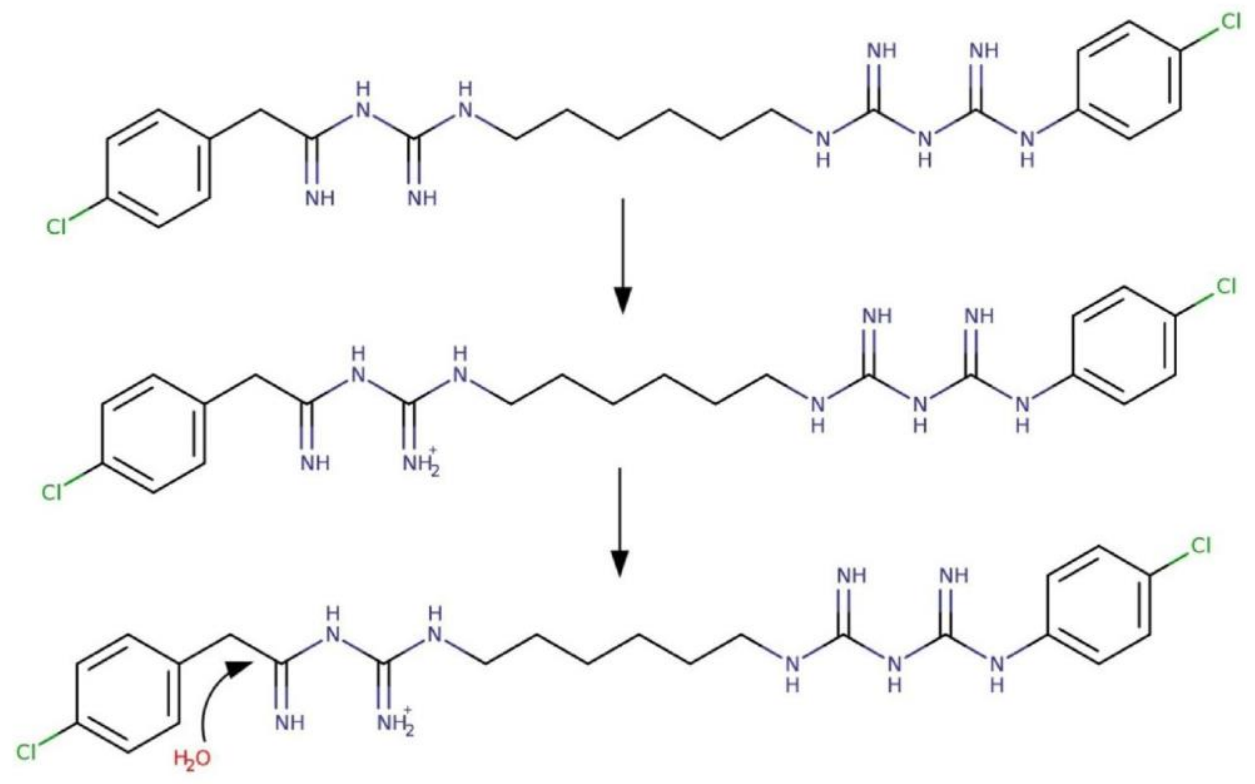

(b)<smiles>N=C(NCCCCCCNC(=N)NC(=O)Nc1ccc(Cl)cc1)NC(=N)Nc1ccc(Cl)cc1</smiles>

(c)<smiles>N=C(NCCCCCCNC(=N)NC(N)=O)NC(=N)Nc1ccc(Cl)cc1</smiles>

Fig. 3. Adapted mechanism proposed by Zong (Leitune et al., 2010) for CHD oxidation: (a) solventattack on monoprotonated CHD; (b) possible degradation products (1): PBGAPU and ammonia; (c) possible degradation products (2): PBG-AU and PCA. 
atoms in the same biguanide unit (N15-N20 and N45-N52) no minimum structure was found. Simultaneous protonation of nitrogen atoms in both sides of the molecule led to the following decreasing order of stability (second DG in Table 2): N15N52 rv N15-N45 > N20-N52 rv N20-N45. The protonation on nitrogen atoms nearer to the ring yields more stable structures, about $6 \mathrm{kcal} \mathrm{mol}^{-1}$ more stable if protonated on N15 than on N20; on the other hand, the difference between N15-N52 and N15-N45 (or $\mathrm{N} 20-\mathrm{N} 52$ and $\mathrm{N} 20-\mathrm{N} 45)$ is about $1.5 \mathrm{kcal} \mathrm{mol}^{-1}$.

If one consider that protonation of $\mathrm{N} 20$ has already occurred, the next protonation should occur on N52 because N20-N52 structure has smaller DG value, being the difference in relation to $\mathrm{N} 20-\mathrm{N} 451.3 \mathrm{kcal} \mathrm{mol}^{-1}$. If we consider that protonation of both atoms occurs at the same time, N15-N52 is the most stable structure, and the energy difference in relation to $\mathrm{N} 20-\mathrm{N} 45$ about $1.6 \mathrm{kcal} \mathrm{mol}^{-1}$. Structures where N15 is protonated present HOMO and HOMO-1 in the same (right) side of the molecule, and more negative DG values. Structures where N2O is protonated present HOMO and HOMO-1 in opposite sides of the molecule. Higher DG values are found for $\mathrm{N} 20-\mathrm{N} 45$ structure, indicating that it is the less probable. The figures of the frontier orbitals mentioned can be found in Supplementary material SM2 and SM3. At pH $<4$ (NCBI, 2015), CHD may have the four $\mathrm{N}$ atoms protonated (four-folded protonated specie in Table 2) and, for this case HOMO and HOMO-1 are in opposite sides of the molecule.

As mentioned before, CHD is symmetric in relation to the hexane chain, but in case of the saturated form, there is a slightly difference in the geometry of both sides, related to the position of the lateral groups. Even though this molecule was obtained as a minimum in potential energy surface, which was confirmed by the absence of imaginary frequencies, we have performed a conformational search using molecular mechanics methodology, followed by DFT optimization and frequency calculation, in order to verify if a more symmetric structure would be viable. In fact, the structures tested presented higher (less negative) free energy values, which suggested that our initial structure is more probable to be found (free energy values and frontier orbitals positions are presented in Supplementary material - SM5 Tables). The symmetry breakdown observed for the initial structure may be due to the formation of two hydrogen bonds (between N15 and H23, and between N45 and H51, Figure SM5), that conducts to the formation of two pseudo-six-membered rings on each side of the molecule, what overstabilizes the molecule. Moreover, the more effective hydrogen bond on the right side of the molecule $(\mathrm{N} 15 \cdots \mathrm{H} 23=$ $1.84 \AA$ A versus and between $\mathrm{N} 45 \cdots \mathrm{H} 51=1.95 \AA$ ) allows HOMO to be distributed along both ring and pseudo-ring.

Since saturated form of neutral CHD is thermodynamically slightly more probable, we conducted the evaluation of oxidation mechanism using this structure. From empirical pKa calculations (Blackburn et al., 2007) and by using the pKa predictor of the MarvinSketch software (ChemAxon, 2015), the protonation form at acidic conditions may vary from two to four nitrogen atoms protonated, and consequently net total charge equals to +2 or +4 . At $\mathrm{pH}=4$, the condition our previous experiments (Sousa et al., 2017) have used, we have analyzed the system with net charges +2 and +4 .

The various degradation pathways described in literature (Zong and Kirsch, 2012; Ha and Cheung, 1996; Revelle et al., 1993) proposed different products and number of steps, even though some intermediate compounds are present in more than one mechanism proposed. The main degradation products were represented in Supplementary material 6. Among the references we have analyzed, some pathways appeared in more than one work. For example, CHD and water leading to PCA and PBG-AU, or PCPU and PBG-G were suggested by Ha and Zong in distinct works, and the difference between them is that Zong started with monoprotonated CHD, while Ha's initial structure is neutral. Zong's descriptions of intermediate products were more detailed, while Ha's work presented only the final products. Based on it, we have chosen some possible pathways to investigate in terms of Gibbs free energy, aiming to analyze the stability of the degradation products if compared with other paths.

Zong suggested in his work that, for monoprotonated CHD, the positive charges would be distributed among all the nitrogen and carbon atoms in the biguanide moiety, so the solvent attack on an electron-deficient carbon would lead to intermediates with potential leaving groups including PCA and ammonia, also giving rise to PBG-AU or PBG-APU. Fig. 3 presents water attack on CHD and the possible final degradation products.

In Table 3 one can compare the DG values of the initial and final products. Between the final products, (1) presents a slightly more negative energy value, being the difference approximately $0.8 \mathrm{kcal}$ $\mathrm{mol}^{-1}$. According to the author, intermediate breakdown leading to the expulsion of PCA would be much more facile than expulsion of ammonia, so pathway (2) would be more probable, but our calculations indicate that both pathways are equally possible. They also suggest that pathway (1) would lead to PCA after more steps, including water attack.

Ha and co-workers (Ha and Cheung, 1996) suggest three main pathways, starting from neutral CHD and leading to different degradation products, and the difference among the paths is where water attacks, i.e., where the breakdown occurs. (Fig. 4). They compare their results with work presented by Elpern (1968), that indicate products derived from path (A) is in tautomeric equilibrium with the ones of path (B). According to Ha and coauthors, the hydrolysis of CHD is likely to proceed via paths (B) and (C), not involving pathway (A). Our results suggest that the more probable path includes PCA formation, in agreement with Elpern's work. Table 3 presents the results of Gibbs free energy for the three pathways suggested by Elpern (1968) and Ha and Cheung (1996). The energy difference between path (A) and path (B) (or (C)) is 0.01607 Hartree, approximately $10 \mathrm{kcal} \mathrm{mol}^{-1}$, indicating that it is the most probable to happen.

\section{Conclusions}

In this work we have used well established computational techniques based on quantum calculations as tools to investigate the degradation process of chlorhexidine, an important an largely used pharmaceutical drug whose degradation products could be toxic, considering as starting point two possible structures, and different protonation states for both cases. For the saturated form of CHD, it was observed that, when we have considered one or two protonated $\mathrm{N}$ atoms, the position of $\mathrm{H}^{+}$influenced the free energy value: if we have one protonation, the structure with $\mathrm{H}^{+}$closer to the hexane chain is more stable; if two simultaneous protonations

Table 3

Gibbs free energy (DG) for CHD, and its comparison with DG of degradation products derived from two different pathways.

\begin{tabular}{lll}
\hline & & DG (a.u.) \\
\hline & $\mathrm{CHD}^{+1}+$ water & -2401.06094 \\
$(1)$ & PBG-APU $+\mathrm{NH}_{3}$ & -2401.08509 \\
$(2)$ & PBG-AU + PCA & -2401.08637 \\
& & \\
(A) & CHD+ water & -2400.67994 \\
(B) & PBG-AU + PCA & -2400.71771 \\
(C) & PCPU + PBG-G & -2400.70164 \\
\hline
\end{tabular}

*(1) and (2) are degradation products suggested by Zong, starting from the monoprotonated CHD, and (A), (B) and (C) are degradation products suggested by $\mathrm{Ha}$, starting from the CHD's neutral form. In both cases it is suggested that the mechanisms occur in presence of water. 
(a)<smiles>N=C(NCCCCCCNC(=N)NC(N)=O)NC(=N)Nc1ccc(Cl)cc1</smiles>

(b)<smiles>N=C(N)NCCCCCCNC(=N)Nc1ccc(Cl)cc1</smiles><smiles>NC(=O)c1ccc(Cl)cc1</smiles>

(c)<smiles>N=C(NCCCCCCNC(N)=O)NC(=N)Nc1ccc(Cl)cc1</smiles><smiles>N=C(N)c1ccc(Cl)cc1</smiles>

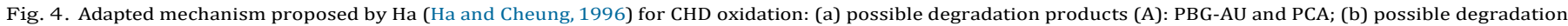
products (B): PCPU and PBG-G; (c) possible degradation products (C): PCPG and PBG-G1.

were considered, the structure with both $\mathrm{H}^{+}$nearer from the chlorinated ring was found as the most stable. It was also investigated different degradation pathways proposed in literature for the CHD's saturated form. Different degradation pathways were investigated, starting from CHD's neutral and monoprotonated forms: our simulations regarding Ha's mechanism (that starts with CHD's neutral form) do not agree with that proposal, since we have observed that the pathway leading to PCA formation was more probable than others. On the other hand, starting from the protonated form, as proposed by Zong et al., the pathway leading to PCA formation with few steps is more likely to happen, and also, PBG-AU in neutral and protonated forms may also be formed. In this sense, such techniques have shown effective to corroborate and mainly complement experimental results.

\section{Acknowledgments}

The authors wish to thank the Brazilian research funding institution CNPq for their financial support through the project CNPqPVE 2014 (Proc. 400223/2014-7 and 303596/2014-7), also

for grants 306177/2016-1 and 154089/2016-8). 


\section{References}

Drugbank DrugBank: Chlorhexidine (DB00878) Available at: https://www. drugbank.ca/drugs/DB00878, (Accessed on October 2017).

Agarwal, A., et al., 2012. Polymeric multilayers that localize the release of chlorhexidine from biologic wound dressings. Biomaterials 33 (28), 6783-6792.

Bharatam, P.V., Patel, D.S., Iqbal, P., 2005. Pharmacophoric features of biguanide derivatives: an electronic and structural analysis. J. Med. Chem..

Blackburn, R.S., Harvey, A., Kettle, L.L., Manian, A.P., Payne, J.D., Russell, S.J., 2007. Sorption of chlorhexidine on cellulose: mechanism of binding and molecular recognition. J. Phys. Chem. B 111, 8775-8784.

BerziÃš, K., Kons, A., Grante, I., Dzabijeva, D., Nakurte, I., ActiÃš, A., 2016. Journal of pharmaceutical and biomedical analysis multi-technique approach for qualitative and quantitative characterization of furazidin degradation kinetics under alkaline conditions K arlis. J. Pharm. Biomed. Anal. 129, 433-440.

ChemAxon, 2015. Marvin 15.6.29. .

Capelle, K., 2006. A Bird's-Eye View of Density-Functional Theory. Braz. J. Phys. 36, 1318-1343.

Elpern, B., 1968. PART I. The background of biguanides: chemistry of the biguanides.

Chem. Biguanides Ann. New York Acad. Sci. 148, 577-586.

Edmiston, C.E., Seabrook, G.R., Johnson, C.P., Paulson, D.S., Beausoleil, C.M., 2007. Comparative of a new and innovative $2 \%$ chlorhexidine gluconate-impregnated cloth with $4 \%$ chlorhexidine gluconate as topical antiseptic for preparation of the skin prior to surgery. Am. J. Infect. Control 35 (2), 89-96.

Fernandes, P.A., Joa, M., 2007. General Performance of Density Functionals. , pp. pp. 10439-10452.

Frisch, M.J., Trucks, G.W., Schlegel, H.B., Scuseria, G.E., Robb, M.A., Cheeseman, J.R., Scalmani, G., Barone, V., Mennucci, B., Petersson, G.A., Nakatsuji, H., Caricato, M., Li, X., Hratchian, H.P., Izmaylov, A.F., Bloino, J., Zheng, G., Sonnenberg, J.L., Hada, M., Ehara, M., Toyota, K., Fukuda, R., Hasegawa, J., Ishida, M., Nakajima, T., Honda, Y., Kitao, O., Nakai, H., Vreven, T., Montgomery Jr., J.A., Peralta, J.E., Ogliaro, F., Bearpark, M., Heyd, J.J., Brothers, E., Kudin, K.N., Staroverov, V.N., Keith, T., Kobayashi, R., Normand, J., Raghavachari, K., Rendell, A., Burant, J.C., lyengar, S.S., Tomasi, J., Cossi, M., Rega, N., Millam, J.M., Klene, M., Knox, J.E., Cross, J.B., Bakken, V., Adamo, C., Jaramillo, J., Gomperts, R., Stratmann, R.E., Yazyev, O., Austin, A.J., Cammi, R., Pomelli, C., Ochterski, J.W., Martin, R.L., Morokuma, K., Zakrzewski, V.G., Voth, G.A., Salvador, P., Dannenberg, J.J., Dapprich, S., Daniels, A.D., Farkas, O., Foresman, J.B., Ortiz, J.V., Cioslowski, J., Fox, D.J., 2010. Gaussian 09, Revision C.01. Gaussian, Inc., Wallingford CT.

Fong, N., Simmons, A., Poole-Warren, L.A., 2010. Antibacterial polyurethane nanocomposites using chlorhexidine diacetate as an organic modifier. Acta Biomater. 6 (7), 2554-2561.

Fernandes, J.G., et al., 2014. PHB-PEO electrospun fiber membranes containing chlorhexidine for drug delivery applications. Polym. Test. 34, 64-71.

Gino DiLabio, A., Otero-de-la-Roza, 2014. Noncovalent interactions in Density- Functional Theory. Rev. Comput. Chem. 29 (May), 1-90.

Geerlings, P., et al., 2003. Conceptual density functional theory. Chem. Rev..

Hugo, W.B., Longworth, A.R., 1964. Some aspects of the mode of action of chlorhexidine. J. Pharm. Pharmacol. 16 (10), 655-662.

Humphrey, W., Dalke, A., Schulten, K., 1996. VMD: visual molecular dynamics. J. Mol. Graph..

Ha, Y., Cheung, A.P., 1996. New stability-indicating high performance liquid chromatography assay and proposed hydrolytic pathways of chlorhexidine. J. Pharm. Biomed. Anal. 1327-1334.

Jones, D.S., Woolfson, A.D., Brown, A.F., 1998. Viscoelastic properties of bioadhesive chlorhexidine containing semisolids for topical application to the oropharynx. Pharm. Res. 15 (7), 1131-1136.

Ji, Q.X., Zhao, Q.S., Deng, J., Lü, R., 2010. A novel injectable chlorhexidine thermosensitive hydrogel for periodontal application: preparation, antibacterial activity and toxicity evaluation. J. Mater. Sci. Mater. Med. 21 (8), $2435-2442$.

Loguercio, A.D., Stanislawczuk, R., Polli, L.G., Costa, J.A., Michel, M.D., Reis, A., 2009. Influence of chlorhexidine digluconate concentration and application time on resin-dentin bond strenght durability. Eur. J. Oral Sci. 117, 587-596.

Lindblad, R.M., Lassila, L.V.J., Salo, V., Vallittu, P.K., Tjäderhane, L., 2010. Effect of chlorhexidine on initial adhesion of fiber-reinforced post to root canal. J. Dent. 38 (10), 796-801.

Leitune, V.C.B., Collares, F.M., Werner Samuel, S.M., 2010. Influence of chlorhexidine application at longitudinal push-out bond strength of fiber posts. Oral Surg. Oral Med. Oral Pathol. Oral Radiol. Endodontol. 110 (5), e77-e81.

Matencio, A., García-Carmona, F., López-Nicolás, J.M., 2017. The inclusion complex of oxyresveratrol in modified cyclodextrins: A thermodynamic, structural, physicochemical, fluorescent and computational study. Food Chem. 232, $177-184$.

NCBI, 2015. PubChem Compound Database; CID = 996. (Online]. Available: https:// pubchem.ncbi.nlm.nih.gov/compound/9552079. [Accessed: 30 July 2015). 
Pusateri, C.R., Monaco, E.A., Edgerton, M., 2009. Sensitivity of Candida albicans biofilm cells grown on denture acrylic to antifungal proteins and chlorhexidine. Arch. Oral Biol. 54 (6), 588-594.

Revelle, L.K., Doub, W.H., Wilson, R.T., Harris, M.H., Rutter, A.M., 1993. Identification and isolation of chlorhexidine digluconate impurities. Pharm. Res. An Off. J. Am. Assoc. Pharm. Sci..

Rapolu, R., et al., 2015. Journal of Pharmaceutical and Biomedical Analysis A novel UV degradation product of Ebastine:

isolation and characterization using Q-TOF, NMR, IR and computational chemistry. J. Pharm. Biomed. Anal. 107, $488-494$. Sousa, C.P., et al., 2017. Chlorhexidine digluconate on chitosan-magnetic iron oxide nanoparticles modified electrode: computational simulations. Sens. Actuators B 240, 417-425.

electroanalysis and mechanistic insights by

Silva, A.R.L., Queiroz, J.L.A., Moura, D.C., Silva, D.R., Martínez-Huitle, C.A., 2017. Electrochemical study of carboxylic acids with $\mathrm{Nb}$-supported boron doped diamond anode. Part 2: electrochemical oxidation associated to DFT calculations. J. Electroanal. Chem. 794 (November (2016)), 93-102.

Van Oosten, B., Marquardt, D., Komljenovic, I., Bradshaw, J.P., Sternin, E., Harroun, T.

A., 2014. Small molecule interaction with lipid bilayers: a molecular dynamics study of chlorhexidine. J. Mol. Graph. Model..

Wang, L.H., Tsai, S.J., 2001. Voltammetric behavior of chlorhexidine at a film mercury electrodes and its determination in cosmetics and oral hygiene products. Anal. Chim. Acta .

Qi, H., Nishihata, T., Rytting, J.H., 1994. Study of the interaction between

b-cyclodextrin and chlorhexidine. Pharm. Res. 11 (8), 1207-1210.

Xue, Y., et al., 2009. High-performance liquid chromatographic determination of chlorhexidine in whole blood by solidphase extraction and kinetics following an intravenous infusion in rats. J. Anal. Toxicol. 33 (March (2)), 85-91.

Zong, Z., Kirsch, L.E., 2012. Studies on the instability of chlorhexidine, part I: kinetics and mechanisms. J. Pharm. Sci.. 